8 Belfrage $\mathrm{P}$, Berge B, Hagerstrand J, Nilsson-Ehle P, Tornqvist $\mathrm{H}$, Wiebe T Alteration of lipid metabolism in healthy volunteers during long term ethanol intake. Eur f Clin Invest 1977;7:127-31.

9 Thornton J, Symes C, Heaton K. Moderate alcohol intake reduces bile cholesterol saturation and raises HDL cholesterol. Lancet 1983;ii:819-22.

10 Haskell WI Camargo C, Williams PT, Vranizan KH, Kraus RM, Lindgren Fr, et al. The effect of cessation and resumption of mode, Lindgren FT, et al. The effect of cessation and resumption of moderate alcohol intake on serum high density lipo

11 Diehl AK, Fuller JM, Mattock MB, Salter AH, el-Gohar R, Keen H. The relationship of high density lipoproteins to alcohol consumption, and other lifestyle factors, and coronary heart disease. Atherosclerosis 1988;69:145-53.
Miller NE, Bolton CH, Hayes TM, Bainton D, Yarnell JWG, Baker IA, et al. Associations of alcohol consumption with plasma high density lipoprotein cholesterol and its major subfractions: the Caerphilly and Speedwell collaborative heart disease studies. F Epidemiol Community Health 1988;42: 220-5.

13 Taskinen MR, Valimaki M, Nikkila EA, Kuusi T, Ehnholm C, Ylikahn R, et al. High density lipoprotein subfractions and post heparin plasma lipases in alcoholic men before and after ethanol withdrawal. Metabolism 1982;31: 1168.

14 Miller NE, Hammett F, Saltissi S, Rao S, Van Zeller H, Coltart J, et al. Relation of angiographically defined coronary artery disease to plasma lipoprotein subfractions and apolipoproteins. BMI 1981;282:1741-4.

15 Ballantyne FC, Clark RS, Simpson MS, Ballantyne D. High density and low density lipoprotein subfractions in survival of myocardial infarction in consity lipoprotein subfractions in survival

16 Hennekens CM, Buring JE, O'Connor GT, Goldhaber SZ, Stampfer MJ, Breslow J, et al. Moderate alcohol consumption and risk of myocardial infarction [abstract]. Circulation 1987;76(suppl iv):501.

17 Pyorala K. Relationship of glucose tolerance and plasma insulin to the incidence of coronary heart disease. Results from two population studies in Finland. Diabetes Care 1979;2:131-4.

18 Ducimetiere P, Eschwege E, Papoz L, Richard JL, Claude JR, Rosselin G, et al. Relationship of plasma insulin levels to the incidence of myocardial infarction and coronary heart disease mortality in middle aged population. Diabetologia 1980;19:205-10.
19 Welborn TA, Wearn K. Coronary heart disease incidence and cardiovascular mortality in Bussetton with reference to glucose and insulin concentration. Diabetic Care 1979;2:154-60.

20 Heaton KW, Braddon FEM, Mountford RA, Hughes AO, Emmett PM Symptomatic and silent gall stones in the community. Gut 1991;32:316-20.

21 Oettle GJ, Emmett PM, Heaton KW. Glucose and insulin responses to manufactured and whole food snacks. Am $\mathcal{F}$ Clin Nutr 1987;45:86-91.

22 Fehily $\mathrm{AM}$, Yarnell JWG, Bolton $\mathrm{CH}$, Butland BV. Dietary determinants of plasma lipids and lipoproteins, the Caerphilly study. Eur $f$ Clin Nutr 1988:42:405-13.

23 Minitab. Reference manual (release 7). Pennsylvania: Minitab, 1989

24 Castelli WP, Doyle JT, Gordon T, Hames CG, Hjortland MC, Hulley SB, et al. Alcohol and blood lipids. Lancet 1977;ii: 153-5.

25 Evans SJW. Good survey guide. BMJ 1991;302:302-3.

26 Criqui $M$, Cowan L, Tyroler A, Bangdirvala S, Heiss G, Wallace RB, et al. Lipoproteins as mediators for the effects of alcohol consumption and cigarette smoking on cardiovascular mortality. Am f Epidemiol 1987;126: 629-37.

27 Patel DG, Singh SP. Effect of ethanol and its metabolite on glucose mediated insulin release from isolated islets of rats. Metabolism 1979;28:85-9.

28 Metz R, Berger S, Mako M. Potentiation of the plasma insulin response to glucose by prior administration of alcohol. Diabetes 1969;18:517-22.

29 Russell JC, Amy RM, Manickavel V, Dolphin PJ. Effect of chronic ethanol consumption in atherosclerotic-prone JCR:LA corpulent rats. Arterioconsumption in atherosc
sclerosis $1989 ; 9: 121-8$.

30 Ohler G, Bleyl $M$, Matthes $\mathrm{KJ}$. Hyperinsulinaemia in hepatic steatosis. Int $f$ Obes 1982;6(suppl 1):137-44.

31 Steiner G. Hypertriglyceridemia and carbohydrate intolerance: interactions and therapeutic implications. Am $\mathcal{F}$ Cardiol 1986;57:27-30G.

32 Dietschy JM, Brown MS. Effect of alterations of the specific activity of the intracellular acetyl CoA pool on apparent rate of hepatic cholesterogenesis. f Lipid Res 1974;15:508-16.

33 Willett WC, Stampfer MJ, Colditz GA, Rosna BA, Hennekens $\mathrm{CH}$ Speizer FE. Moderate alcohol consumption and the risk of breast cancer. N Engl F Med 1987;316:1174-80.

(Accepted 30 October 1991)

\title{
Effect of "fast track" admission for acute myocardial infarction on delay to thrombolysis
}

\author{
Alastair C H Pell, Hugh C Miller, Colin E Robertson, Keith A A Fox
}

\section{Abstract}

Objective-To evaluate the impact of a fast track triage system for patients with acute myocardial infarction.

Design-Comparison of delays in admission to hospital and in receiving thrombolytic treatment before and after introducing fast track system with delays recorded in 1987-8. Patients fulfilling clinical and electrocardiographic criteria for myocardial infarction were selected for rapid access to the cardiac care team, bypassing evaluation by the medical registrar.

Setting-Major accident and emergency, cardiac and trauma centre.

Subjects - 359 patients admitted to the cardiac care unit during 1 February to 31 July 1990 with suspected acute infarction.

Main outcome measures-Accuracy of diagnosis and delay from arrival at hospital to thrombolytic treatment.

Results -248 of the 359 patients had myocardial infarction confirmed, of whom 127 received thrombolytic treatment. The fast track system correctly identified 79 out of $127(62 \%)$ patients who subsequently required thrombolytic treatment. $95 \%$ (79/83) of patients treated with thrombolysis after fast track admission had the diagnosis confirmed by electrocardiography and enzyme analysis. The median delay from hospital admission to thrombolytic treatment fell from 93 minutes in 1987-8 to 49 minutes in fast track patients $(p<0.001)$. Delay in admission to the cardiac care unit was reduced by $47 \%$ for fast track patients (median 60 minutes in 1987-8 $v 32$ minutes in $1990, \mathrm{p}<0.001$ ) and by $25 \%$ for all patients (60 minutes $v 45$ minutes, $\mathrm{p}<0.001$ ).

Conclusion-This fast track system requires no additional staff or equipment, and it halves inhospital delay to thrombolytic treatment without affecting the accuracy of diagnosis among patients requiring thrombolysis.

\section{Introduction}

Experimentally and clinically prognosis after acute myocardial infarction is dependent on the duration of myocardial ischaemia..$^{1-7}$ Although clinical benefit has been shown with thrombolysis in patients presenting more than six hours after onset of symptoms of myocardial infarction, very early thrombolytic treatment maximises the functional and survival benefits. ${ }^{8-12}$ Delay in the hospital constitutes an important and potentially avoidable component of the total delay. Studies in major cardiac centres in the United States and Europe report hospital delays of 50130 minutes. $.^{23} 13-15$ Practical triage systems for minimising such delay have not yet been established.

An audit of patients admitted to our hospital in 1987-8 found median delays from arrival to thrombolysis of 93 minutes, and the delay in patients with unequivocal electrocardiographic evidence of acute myocardial infarction was no shorter than in patients with suspected myocardial infarction. ${ }^{16}$ A relatively small proportion of patients $(23 \%$ of those with infarction) received thrombolytic treatment. The audit identified several factors that contributed to inhospital delay, including triplication of patient assessment by accident and emergency staff, the duty medical registrar, and the cardiac care team. The triage system was common to all medical emergencies and the requirement for thrombolysis was assessed only after admission to cardiac care unit.

Edinburgh Royal Infirmary is the main accident and emergency and trauma centre for the Lothian region and in 1990, 68641 new patients were evaluated. A duty medical registrar received all emergency medical referrals and was responsible for their initial evalua- 
tion, treatment, and transfer. In 1990, 1243 patients were admitted to the cardiac care unit and 10755 patients were discharged from acute medical wards. Thus patients with acute myocardial infarction patients constituted only one part of the duty medical registrar's heavy workload.

To minimise each of the components of inhospital delay we devised and introduced a "fast track" admission system. In other hospitals a fast track system has been devised in which patients with infarction were identified before reaching hospital by paramedic ambulance staff and staff of the emergency department. ${ }^{17}$ However, as yet, systems using paramedic ambulance staff have had limited applicability. The principles of the Edinburgh fast track system were: to permit very early identification of patients with clear cut myocardial infarction; to avoid multiple assessments of patients and the concomitant delays; and to permit the cardiac care team to evaluate and treat patients in the emergency department or the cardiac care unit.

In the fast track triage system patients are selected for treatment by the cardiac care team by using predefined clinical and electrocardiographic criteria, and routine evaluation by the duty medical registrar is bypassed. The cardiac care team establishes the diagnosis and initiates thrombolytic treatment in the emergency department or the cardiac care unit. We evaluated the system's impact in the first six months after its introduction.

\section{Subjects and methods}

Before the fast track system was implemented we examined the admission patterns during 1-31 January 1990 to determine whether the patterns had changed appreciably since the previous detailed audit during 1 August 1987 to 31 January $1988 .{ }^{16}$

A simplified protocol for fast track admission of patients with myocardial infarction (figure) was agreed with the consultant physicians in the specialty group in medicine, the junior medical staff, and the emergency department staff. The protocol was displayed in the emergency department and junior medical staff were encouraged to adopt the protocol. After an instruction phase of about one month, the fast track system was implemented on 1 February 1990. This report includes all patients presenting from outside the hospital with

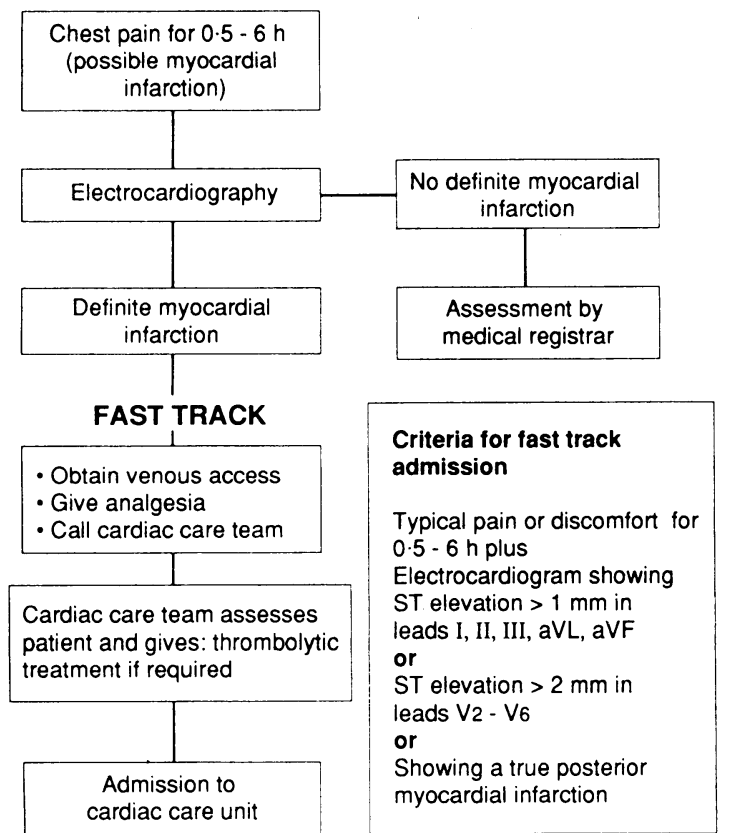

Fast track admission system for patients with acute myocardial infarction
TABLE I-Patients with myocardial infarction confirmed at discharge: those receiving thrombolytic treatment and those not fulfilling criteria for treatment during six months in 1987-8 16 and 1990

\begin{tabular}{lcc}
\hline & $\begin{array}{c}\text { No (\%) of } \\
\text { patients 1987-8 } \\
(\mathbf{n}=237)\end{array}$ & $\begin{array}{c}\text { No(\%) of } \\
\text { patients 1990 } \\
(\mathbf{n}=248)\end{array}$ \\
\hline Received thrombolysis & $54(23)$ & $127(51)$ \\
No thrombolysis & $183(77)$ & $121(49)$ \\
Reasons for not treating: & $80(34)$ & $56(23)$ \\
$\quad$ Electrocardiogram not diagnostic & $49(21)$ & $22(9)$ \\
Onset of symptoms $>$ 6 h previously & $7(3)$ & $6(2)$ \\
Peptic ulcer & $20(8)$ & 0 \\
Age >70 years & $27(11)$ & $37(15)$ \\
\hline Miscellaneous & & \\
\hline
\end{tabular}

${ }^{\star}$ Includes traumatic resuscitation, bleeding diathesis, and hypertension.

suspected acute myocardial infarction over the six months from 1 February to 31 July 1990. Transfers from other units within the Royal Infirmary or from other hospitals were excluded from the analysis.

The protocol specified that all patients who clearly fulfilled the defined clinical and electrocardiographic criteria for myocardial infarction would be admitted by the fast track route and the remainder, in whom the diagnosis was uncertain, would be formally evaluated by the medical registrar. We compared the results with those obtained in the $1987-8$ audit. ${ }^{16}$ In contrast with the policy in 1987-8 there was no upper age limit to thrombolytic treatment. The appendix gives the inclusion and exclusion criteria for thrombolytic treatment during the study. The Mann-Whitney test was used to determine the significance of differences between median times.

\section{Results}

Analysis of admissions in the period before the fast track policy was implemented showed that the inhospital delays were similar to those during the 1987-8 audit. The median time between arrival at hospital and admission to the cardiac care unit was 55 minutes and the time to initiation of thrombolytic treatment was 92 minutes after hospital admission (210 minutes after onset of symptoms; 59 patients, 25 treated with thrombolysis).

Between 1 February and 31 July 1990, 359 patients were admitted to the cardiac care unit with suspected acute myocardial infarction. At discharge, $248(69 \%)$ of these had had myocardial infarction confirmed. In a further 90 patients $(25 \%)$ the final diagnosis was unstable angina, and in $21(6 \%)$ there were other diagnoses (predominantly atypical chest pain). During the $1987-8$ audit 352 patients had been admitted with suspected myocardial infarction and a similar proportion $(237(67 \%))$ had had the diagnosis confirmed.

Of the 248 patients with confirmed myocardial infarction in 1990, $127(51 \%)$ received thrombolytic treatment. Nine patients in whom acute myocardial infarction was not confirmed also received thrombolytic treatment. Only 54/237 (23\%) patients received thrombolytic treatment during the previous audit.

Table I shows the numbers of patients with acute myocardial infarction who did and did not receive thrombolytic treatment. Failure to meet the electrocardiographic criteria or symptoms of more than six hours' duration were the reasons for non-treatment in $129(54 \%)$ patients with confirmed infarction in 1987-8 and $78(31 \%)$ patients in 1990.

\section{ACCURACY OF INITIAL DIAGNOSIS}

The 112 patients admitted by the fast track route all had an initial diagnosis of suspected acute myocardial infarction. At discharge $96(86 \%)$ had the diagnosis confirmed, based on electrocardiographic and enzyme determinations. Thrombolytic treatment was given to 83 patients, of whom $79(95 \%)$ had myocardial infarction confirmed by electrocardiographic and enzyme 
criteria (table II). Among the remaining four patients, one had acute pericarditis diagnosed and in three the electrocardiograms suggested acute myocardial infarction with reperfusion (early ST resolution) but a rise in cardiac enzyme concentrations was not seen (possibly representing "aborted" infarction).

Of 247 patients admitted by the non-fast track route, 53 fulfilled electrocardiographic criteria for acute myocardial infarction and all 53 received thrombolysis. Forty eight $(91 \%)$ of these had a final diagnosis of acute myocardial infarction. Of the remaining patients admitted by the non-fast track route, 104 had an eventual diagnosis of myocardial infarction and $95 \mathrm{had}$ other diagnoses including angina and non-cardiac pain. Overall, nine of the 359 patients (four admitted by fast track system) received thrombolytic treatment but showed no rise in cardiac enzyme concentrations to confirm infarction. In none of these nine patients did the final diagnosis involve another organ system, and no patient with aortic dissection received thrombolysis.

The apparent false positive rate for thrombolytic treatment (true positives were defined as patients with electrocardiographic and enzymic confirmation) was $5 \%(4 / 83)$ for the fast track admissions and 9\% (5/53) for the other admissions. However, the fast track system aims at selecting patients who clearly meet electrocardiographic criteria and hence these false positive rates are not comparable. Furthermore, a rise in enzyme concentrations is aborted in a few patients treated very early after the onset of myocardial infarction, and in some patients sufficient numbers of enzyme estimations may not have been undertaken to exclude an increased concentration. Of the 127 patients with acute myocardial infarction eligible for thrombolytic treatment (based on diagnosis at discharge), $79(62 \%)$ were identified by the emergency department staff and admitted by the fast track system.

\section{COMPARISON OF TIME DELAYS BETWEEN 1987-8 AND 1990}

Overall, the time from hospital admission to treatment with thrombolysis was reduced from a median of 93 minutes in 1987-8 to 49 minutes for patients admitted by the fast track system and to 52 minutes for all patients in $1990(\mathrm{p}<0.001)$. After the fast track

TABLE II-Confirmed myocardial infarction and thrombolytic treatment in patients admitted by the fast track and non-fast track systems during six months in 1990. Numbers in parentheses are percentages

\begin{tabular}{|c|c|c|}
\hline & $\begin{array}{c}\text { Fast track } \\
\text { admissions } \\
(\mathbf{n}=112)\end{array}$ & $\begin{array}{c}\text { Non-fast track } \\
\text { admissions } \\
(\mathrm{n}=247)\end{array}$ \\
\hline Myocardial infarction confirmed & $96(86)$ & $152(62)$ \\
\hline Thrombolysis & 79 & 48 \\
\hline No thrombolysis & 17 & 104 \\
\hline Myocardial infarction not confirmed & $16(14)$ & $95(38)$ \\
\hline Thrombolysis & 4 & 5 \\
\hline No thrombolysis & 12 & 90 \\
\hline
\end{tabular}

TABLE III-Median inhospital delays and delays to thrombolysis in patients with suspected acute myocardial infarction during six months in 1987-8 16 and 1990

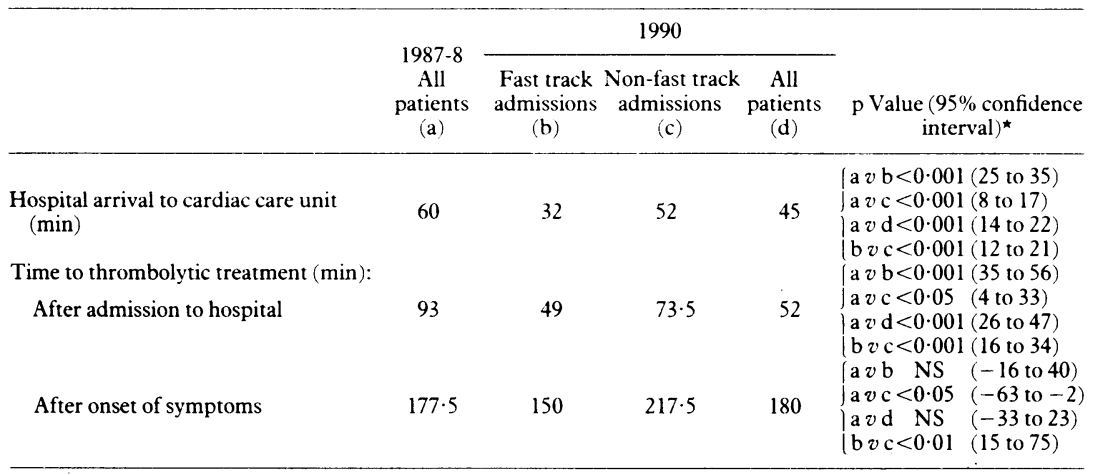

$\star 95 \%$ Confidence interval for differences in median times.
TABLE IV-Time from arrival at hospital to admission to cardiac care unit during six months in $1987-8^{16}$ and 1990

\begin{tabular}{lcc}
\hline Time (minutes) & $\begin{array}{c}\text { No }(\%) \text { of all } \\
\text { patients 1987-8 } \\
(\mathbf{n}=352)^{\star}\end{array}$ & $\begin{array}{c}\text { No (\%) of fast track } \\
\text { patients 1990 } \\
(\mathbf{n}=112)\end{array}$ \\
\hline $0-15$ & $7(20)$ & $4(4)$ \\
-30 & $32(10)$ & $43(38)$ \\
-45 & $44(13)$ & $37(33)$ \\
-60 & $85(26)$ & $15(13)$ \\
-75 & $56(17)$ & $7(6)$ \\
-90 & $44(13)$ & $5(4)$ \\
-105 & $20(6)$ & $1(1)$ \\
-120 & $26(8)$ & 0 \\
-135 & $3(1)$ & 0 \\
$\geqslant 136$ & $14(4)$ & 0
\end{tabular}

«331 Patients with full information on timing

system was introduced the time between admission to hospital and admission to the cardiac care unit was reduced for the fast track admissions by $47 \%(60$ minutes in 1987-8 $v 32$ minutes in 1990) and $25 \%$ for all patients ( 60 minutes $v 45$ minutes) (table III). Table IV gives the distribution of delays for all admissions in 1987-8 and for fast track admissions in 1990. Overall, the median times to admission to the cardiac care unit and to thrombolytic treatment were significantly shorter in 1990 compared with 1987-8 ( $p<0.001$ for both). The fast track route significantly shortened inhospital delays $(p<0.001)$ and total time to thrombolytic treatment $(p<0.001)$ in comparison with the nonfast track route. Between 1987-8 and 1990 the delay in getting to hospital lengthened (79 minutes in 1987-8 $v$ 107 minutes in 1990), and consequently the overall delay from the onset of symptoms to treatment was not significantly altered (table III).

\section{Discussion}

The fast track system correctly identified nearly two thirds of all the patients who subsequently were shown to have required thrombolytic treatment, and it reduced inhospital delays to thrombolysis. During the period of analysis, no patient sustained evidence of embolic or haemorrhagic stroke and no patient required transfusion for bleeding complications.

In the 1987-8 audit we showed that inhospital delays contributed substantially to the total duration of ischaemia in patients with acute myocardial infarction. ${ }^{16} \mathrm{~A}$ median of 60 minutes elapsed between arrival in the emergency department and arrival in the cardiac care unit, with an additional 30 minutes before thrombolytic therapy was started. The fast track admission system, which required no extra staff or equipment, has halved the inhospital delay for patients with clear evidence of infarction. Furthermore, inhospital delays for all patients admitted to the cardiac care unit with suspected acute myocardial infarction were cut by $25 \%$. In January 1990 , immediately before the fast track system was introduced, the inhospital delay was similar to that in 1987-8 despite an active thrombolysis programme and a written policy for identifying patients for thrombolysis.

In 1987-8 a relatively small proportion of patients with acute infarction received thrombolytic treatment $(23 \%)$ in comparison with half of such patients in 1990 . The removal of an age restriction for thrombolysis in the cardiac care unit has contributed to the increase in thrombolytic treatment and resulted in an older population distribution $17 \%$ of patients aged $>70$ years in $1990 v$ none in 1987-8). Previous studies have shown that elderly people experience longer delays, especially before reaching hospital. ${ }^{18}$

The high proportion of patients with confirmed myocardial infarction in the cardiac care unit is a reflection of shortage of intensive care beds rather than an ideal practice (eight beds with an average occupancy of $73 \%$ ). The fast track system has not 
increased inappropriate referrals to the cardiac care unit. For both the fast track and non-fast track routes over $90 \%$ of patients admitted with suspected infarction and given thrombolytic treatment had the diagnosis confirmed. Although nine patients given thrombolytic treatment did not show increased enzyme concentrations, in none of these did the final diagnosis involve another organ system. Failure to show increased enzyme concentrations may also reflect reperfusion and "aborted" myocardial infarction.

Maintenance of the fast track system requires coordinated training of cardiac and emergency department staff, periodic audit, and the review of data on all patients delayed more than 15 minutes in the emergency department. It necessitates 24 hour availability of the cardiac care team. Our fast track system has the advantage of not requiring all junior emergency department staff to be familiar with the inclusion and exclusion criteria for thrombolysis. This is particularly relevant to those departments that have a high and regular turnover of junior medical staff. The fast track system removes patients with clear evidence of infarction from general medical assessment, and we found no evidence that the remainder of patients suffered additional delays. Indeed, patients with ambiguous features, admitted by the medical registrar, had delays reduced by $13 \cdot 3 \%$ (table III).

\section{COMPARISON WITH OTHER STUDIES}

In North America, inhospital delays of 50 to 130 minutes have been reported in major cardiac centres ${ }^{13} 14$ and similar figures have been obtained in Europe and in Britain. ${ }^{2315}$ Among American men entered into a large study of thrombolysis the median delay to thrombolysis was 4.9 hours and only a fifth of men were treated within two hours of onset of symptoms. ${ }^{19}$ Thus the findings in the 1987-8 audit in Edinburgh were not atypical for major cardiac centres, although unacceptable in the era of thrombolysis. In our present study the median times from onset of symptoms to thrombolysis were 2.5 hours for fast track patients and $3 \cdot 6$ hours for other patients.

Would thrombolysis before reaching hospital provide a feasible alternative for minimising delay? In the Seattle experience there was a potential time saving of about 60 minutes, but only $4 \%$ of patients with suspected myocardial infarction were eligible for treatment before arriving at hospital..$^{20}$ In that study thrombolysis was administered in hospital, a median of 1.9 hours after onset of symptoms. The large scale European study (EMIP) is randomising patients before hospital and inhospital treatment by using mobile intensive care units staffed by doctors and has reported a time gain of about 60 minutes when treatment is given before reaching hospital but a median delay of $2 \cdot 2$ hours from symptom onset (comparable with the delay with inhospital treatment in our study). ${ }^{21}$ An alternative strategy would be direct access to the cardiac care unit, but this requires sufficient beds to admit patients to rule out infarction and a suitable triage area for managing patients with non-cardiac conditions. ${ }^{22}$

Our study shows that changes in hospital practice can substantially reduce the delay to thrombolysis. Studies of thrombolysis treatment before patients reach hospital should therefore be compared with optimal rather than historical inhospital treatment. Our study was conducted during a period of heavy clinical demand and restricted bed availability, and the findings cannot be regarded as reflecting optimal treatment. Further reductions might be achieved if thrombolytic treatment could be started in the emergency department with minimal delay. In our hospital emergency priorities and availability of space have restricted the application of thrombolysis in the emergency department. Bolus administration systems may obviate this problem.

Although simple in design, the fast track system necessitated a change in working practice for the emergency department, the cardiac care unit, five acute medical receiving units, and the technical and paramedical staff. The system could not have been implemented if the senior house officer in the cardiac care unit had shared responsibility for other aspects of care. The main time savings achieved with the fast track system are a consequence of a clear, fully implemented policy which avoids duplicate assessments and which identifies patients with a high probability of acute infarction. The fast track system may be useful in other regional cardiac centres and district general hospitals.

We thank Dr R A Elton, Department of Public Health Medicine, for advice and help with statistical analysis.

\section{Appendix}

Criteria for thrombolytic treatment were: history consistent with acute myocardial infarction; ST segment elevation of $>1 \mathrm{~mm}$ in limb leads or $>2 \mathrm{~mm}$ in precordial leads or ST segment depression in precordial leads consistent with early posterior myocardial infarction; and onset of symptoms within six hours.

Specific exclusion criteria included previous history of cerebral haemorrhage, cerebrovascular accident within past two months, severe hypertension (diastolic pressure $>120 \mathrm{~mm} \mathrm{Hg}$ ), recent traumatic resuscitation, a history of gastrointestinal or urinary bleeding within six months, surgery or head injury within one month, diabetic proliferative retinopathy, bleeding diathesis, warfarin treatment, and pregnancy.

Streptokinase was the drug of choice unless it had been given between five days and one year previously. Under these conditions alteplase was given.

Gruppo Italiano per lo Studio della Streptochinasi nell' Infarcto Miocardio (GISSI). Effectiveness of intravenous thrombolytic treatment in acute myocardial infarction Lancet 1986;i:397-402.

2 ISIS-2 (Second International Study of Infarct Survival) Collaborative Group. Randomised trial of intravenous streptokinase, oral aspirin, both, or neither among 17187 cases of suspected acute myocardial infarction: ISIS-2. Lance 1988;ii:349-60.

3 AIMS Study Group. Effect of intravenous APSAC on mortality after acute myocardial infarction: preliminary report of a placebo-controlled trial. Lancet 1988; ; :545-9.

4 Knabb RM, Bergmann SR, Fox KAA, Sobel BE. The temporal pattern of recovery of myocardial perfusion and metabolism delineated by positron emission tomography after coronary thrombolysis. $\mathcal{F} \mathrm{Nucl} \mathrm{Med} \mathrm{1987;28:}$ 1563-70.

5 Koren G, Weiss AT, Hasin Y, Applebaum D, Welber S, Rozenman Y, et al. Prevention of myocardial damage in acute myocardial ischemia by early treatment with intravenous streptokinase. N Engl f Med 1985;313:1384-9.

6 Sheehan FH, Mathey DG, Schofer J, Krebber H, Dodge HT. Effect of interventions in salvaging left ventricular function in acute myocardial infarction: a study of intracoronary streptokinase. Am $\mathcal{Y}$ Cardiol 1983;52: infarction.

7 Van de Werf F, Arnold AER. Intravenous tissue plasminogen activator and size of infarct, left ventricular function and survival in acute myocardial size of infarct, left ventricular functio

8 Castaigne AD, Herve C, Duval-Moulin A, Gaillard M, Dubois-Rande J, Boesch C, et al. Prehospital use of APSAC: results of a placebo-controlle study. Am f Cardiol 1989;64:30-3A.

9 Bossaert LL, Demey HE, Colemont LJ, Beaucourt L, Fierens H, Dirix L, et al. Prehospital thrombolytic treatment of acute myocardial infarction with anisoylated plasminogen activator complex. Crit Care Med 1988;16:823-30.

10 McNeill AJ, Flannery DJ, Wilson CM, Dalzell GWN, Campbell NPS Khan MU, et al. Thrombolytic therapy within one hour of the onset of acute myocardial infarction. Q f Med 1991;79:290;487-94.

11 Roth A, Barbash GI, Hod H, Miller HI, Rath S, Moclan MA, et al. Should thrombolytic therapy be administered in the mobile intensive care unit in patients with evolving myocardial infarction? A pilot study. $f$ Am Coll Cardiol 1990;15:932-6.

12 Fox KAA. Thrombolysis and the general practitioner. BMF 1990;300:867-8.

13 Passami E, Hodges $M$, Herman M, Grose R, Chaitman B, Rogers W, et al. The thrombolysis in myocardial infarction (TIMI) phase II pilot study: The thrombolysis in myocardial infarction (TMI) phase II pilot study: tissue-plasminogen activator followed by percutaenous trans
coronary angioplasty. $\mathcal{F}$ Am Coll Cardiol 1987;10(suppl):51-64B.

14 Sharkey SW, Brunette DD, Ruiz E, Hession WT, Wyshorn DG, Goldenber $\mathrm{IF}$, et al. An analysis of time delays preceding thrombolysis for acute myocardial infarction. FAMA 1989:262:3171-4.

15 Wilcox RG, von der Lippe G, Olsson CG, Jensen G, Skene AM, Hampton JR Trial of tissue plasminogen activator for mortality reduction in acute myocardial infarction: Anglo-Scandinavian study of early thrombolysis (ASSET). Lancet 1988;ii:525-30.

16 Pell ACH, Miller HC. Delays in admission of patients with acute myocardia infarction to coronary care: implications of thrombolysis. Health Bull 1990;48:225-31. 
17 MacCallum AG, Stafford PJ, Jones C, Vincent R, Perez-Avila C, Chamberlain $\mathrm{DA}$. Reduction in hospital time to thrombolytic therapy by audit of policy guidelines. Eur Heart F 1990;11 (suppl F):48-52.

18 Rawles JN, Haites NE. Patient and general practitioner delays in acute myocardial infarction. BMF 1988;296:882-4.

19 Ridker P, Buring J, Manson J, Goldhaber S, Hennekens C. Time to presentation for acute MI in the US Physicians' Health Study. I Am Coll Cardiol 1990;15(suppl 2):167A.

20 Weaver WD, Eisenberg MS, Martin JS, Litwin PE, Schaeffer SM, Ho MT, et al. Myocardial infarction triage and intervention project - phase I: patient characteristics and feasibility of prehospital initiation of thrombolytic therapy. F Am Coll Cardiol 1990;15:925-30.

21 European Myocardial Infarction Project (EMIP) Subcommittee. Potentia time saving with pre-hospital intervention in acute myocardial infarction Eur Heart f 1988;9:118-24.

22 Burns JMA, Hogg KJ, Rae AP, Hillis WS, Dunn PG. Impact of a policy of direct admission to a coronary care unit on use of thrombolytic therapy. Br Heart f 1989;61:322-5.

\title{
Irritable bowel syndrome in the general population
}

\author{
Roger Jones, Susan Lydeard
}

\section{Abstract}

Objective-To determine the prevalence of symptoms compatible with a clinical diagnosis of irritable bowel syndrome in the general population.

Design-Validated postal questionnaire sent to 2280 subjects randomly selected in 10 year age bands from the lists of eight general practitioners. The Manning criteria were used to define irritable bowel syndrome.

Setting-Urban population in Southampton and mixed urban-rural population in Andover, Hampshire.

Results -A response of $71 \%$ yielded 1620 questionnaires for analysis, of which $412(25 \%)$ reported more than six episodes of abdominal pain in the preceding year, with $350(22 \%)$ reporting symptoms consistent with the diagnosis of irritable bowel syndrome. The male: female ratio was $1: 1.38$. More subjects with irritable bowel syndrome had constipation and diarrhoea and $35 \%$ with the syndrome reported rectal bleeding compared with an overall prevalence of $20 \%$. Other symptoms and conditions including heartburn, dyspepsia, flushing, palpitations, migraine, and urinary symptoms were significantly more common in the group with irritable bowel syndrome. Abdominal pain in childhood was more common in the subjects with irritable bowel syndrome $(12 \%)$ than without $(3 \%)$. One third of the group with irritable bowel syndrome had sought medical advice during the study period (male: female ratio 1:1.21); consultation behaviour was influenced by age and the presence of associated symptoms, varied considerably among patients registered with different general practitioners, and was poorly correlated with symptom severity.

Conclusion-Symptoms consistent with a diagnosis of irritable bowel syndrome are present in almost one quarter of the general population and tend to be associated with a number of other complaints and conditions, some of which may reflect smooth muscle dysfunction.

University of

Southampton,

Southampton

Roger Jones, FRCGP, senior

lecturer in primary medical

care

Susan Lydeard, BSC, research officer

Correspondence to:

Professor Roger Jones, Division of Primary Health Care, Medical School, Newcastle upon Tyne NE2 4HH.

BMF 1992;304:87-90

\section{Introduction}

The irritable bowel syndrome is the commonest functional gastrointestinal disorder seen in both primary and secondary care, ${ }^{12}$ and studies have shown that symptom complexes compatible with the clinical diagnosis of irritable bowel syndrome may be present in up to $30 \%$ of the general population. ${ }^{34}$ Most people with gastrointestinal symptoms never consult doctors about them ${ }^{s}$; previous studies on dyspepsia, for example, have shown that concern about the possible serious significance of symptoms is a major determinant of consultation behaviour. ${ }^{6}$ This is likely to be true for irritable bowel syndrome also.

Traditionally, irritable bowel syndrome has been a diagnosis of exclusion, made only after organic disease has been ruled out by investigation. Unnecessary investigations not only involve costs to the health services but also may increase diagnostic uncertainty and heighten patients' anxiety. In an attempt at greater precision, Manning and his coworkers reported the prevalence of 15 symptoms in irritable bowel syndrome and compared these with symptoms in patients with organic disease. ${ }^{7}$ They concluded that six cardinal symptoms discriminated the painful variant of irritable bowel syndrome from organic bowel disease. The more of these six symptoms that were present, the more likely it was that the patients had irritable bowel syndrome. Subsequently Thompson examined the discriminatory value of four symptoms - abdominal pain relieved by defecation, abdominal distension, and both looser and more frequent bowel movements with the onset of pain - and concluded that if two or more of these symptoms are present irritable bowel syndrome could be discriminated from peptic ulcer or organic bowel disease. ${ }^{8}$ Talley and colleagues have evaluated the reliability and discriminatory value of the Manning criteria in irritable bowel syndrome by using an objective self report questionnaire. ${ }^{9}$ Their findings suggest that these criteria can discriminate subjects with all forms of the syndrome from healthy controls and also from patients with organic gastrointestinal disease, although a recent study has cast some doubt on the diagnostic utility of the Manning criteria in men. ${ }^{10}$

There is also interesting evidence of disease associations with irritable bowel syndrome. A substantial number of patients also have abnormalities of bladder detrusor muscle function," and asssociations with a variety of urinary and gynaecological symptoms and with headache have been noted..$^{12}$ Most recently, patients with irritable bowel syndrome and without respiratory symptoms have been shown to have abnormally responsive airways after methacholine challenge, compared with normal controls and patients with organic bowel disease. ${ }^{14}$ The possibility that a generalised smooth muscle abnormality underlies all these conditions is a subject of considerable research and potential therapeutic interest.

Irritable bowel symptoms are common in the general population and in patients with organic disease, ${ }^{15}$ and the predictive value of any criteria will vary according to the prevalence of the disease in the population being assessed. Most people with symptoms will not present for medical care and it is possible that the symptomatology of presenting and non-presenting patients is different. ${ }^{34}$ Heaton's group, for example, has recently reported more severe abnormalities of bowel function, as well as more severe pain, in outpatients with irritable bowel syndrome compared with subjects with symptoms of irritable bowel syndrome identified in a community survey who had not sought medical attention. ${ }^{16}$ Other reports, however, have suggested that it is more likely that sociocultural factors, rather than the type or severity of symptoms, lead to differential health seeking behaviour in those suffering from irritable bowel syndrome, ${ }^{17-20}$ suggesting that the 